\title{
Association Between The Polymorphism of MMP-1 Gene with Knee Osteoarthritis Risk: A Meta-Analysis
}

\author{
Feifan Lu \\ peking unversity \\ Xiaowei Sun \\ Chinese Academy of Medical Sciences and Peking Union Medical College \\ Weiguo Wang \\ China-Japan Friendship Hospital \\ Qidong Zhang ( $\nabla$ zhangqidong1982@pku.edu.cn ) \\ China-Japan Friendship Hospital https://orcid.org/0000-0002-1466-1729 \\ Wanshou Guo \\ China-Japan Friendship Hospital
}

\section{Research article}

Keywords: MMP-1, polymorphisms, knee osteoarthritis, meta-analysis

Posted Date: August 5th, 2020

DOI: https://doi.org/10.21203/rs.3.rs-51711/v1

License: (c) (i) This work is licensed under a Creative Commons Attribution 4.0 International License. Read Full License 


\section{Abstract}

Background: The existing studies on the association between polymorphisms of Matrix metalloproteinase-1 (MMP-1) (-1607 1G/2G) (rs1799750) polymorphism and the risk of knee osteoarthritis (OA, a complex multifactorial disease and a major degenerative form of arthritis) in different populations have yielded conflicting findings.

Method: Literature search was performed in PubMed, Cochrane Library, Web of science, Google Scholar (From January 1990 to June 2019), and assessing this association by calculating odds ratios with $95 \%$ confidence intervals. Subgroup analyses stratified by ethnicity were also conducted. Statistical heterogeneity was quantitatively evaluated by $\mathrm{X}^{2}$ test with the significance set $\mathrm{P}<0.10$ or $\mathrm{I}^{2}>50 \%$.

Result: Five case-control based studies (924 cases and 928 controls) were included. The results suggested that the MMP-1 (-1607 1G/2G) (rs1799750) gene polymorphisms were not associated with knee OA risk in all genetic models (Allele model OR $=1.22,95 \% \mathrm{Cl}$ : 0.72-1.76, $p=0.615$, Recessive model OR $=1.12,95 \% \mathrm{Cl}: 0.70-2.15, p=0.486$, and Dominant model $\mathrm{OR}=1.14,95 \% \mathrm{Cl}: 0.64-2.04, p=0.659$, Figure 3-5)

Conclusions: There is no association between the polymorphism of MMP-1 (-1607 1G/2G) (rs1799750) polymorphism with the risk of knee osteoarthritis, a large number of studies may be necessary to verify this association in different populations and environmental factors.

\section{Background}

Knee osteoarthritis (OA) is a common disease in people over 55 years of age. The incidence of KOA is more than $10 \%$, and a quarter of the patients are severely disabled[1]. Knee OA is a common joint disease which is characterized by degeneration of the articular cartilage and subsequent subchondral bone changes. Knee $\mathrm{OA}$ is a combined result of environmental and genetic factors, while genetic factors account for nearly $50 \%$ of the risk of OA development[2].Although the underlying mechanisms remain unknown, many studies have shown that the occurrence of knee osteoarthritis is related to cytokines, including Matrix metalloproteinases (MMPs) family[3-7].

Matrix metalloproteinase-1 (MMP-1)is produced by synovial cells, chondrocytes, and osteoblasts, which can degrade extracellular matrix collagen and mediate cartilage destruction[7-8]. The expression of MMPs has been shown to be affected by single nucleotide polymorphisms (SNPs) occurring in MMP gene promoters[9]. These promoter polymorphisms have allele-specific effects on the regulation of MMP gene transcription and are associated with the development and/or progression of some common diseases[3-5]. Matrix metalloproteinases secreted from chondrocytes are the main enzymes responsible for pathological cartilage destruction [6].Expression of MMP-1 is low in normal cells that leads to healthy cartilage remodeling. In pathological conditions, the level of MMP-1 expression increases significantly, resulting in aberrant connective tissue destruction[10]. MMP-1 is expressed at higher levels in OA chondrocytes than in normal chondrocytes, suggesting a predominant role of MMP-1 in OA pathogenesis[11].

MMP-1 (-1607 1G/2G) (rs1799750) has been shown to affect the transcriptional activity of its genes. The two alleles of MMP1 (-1607) gene polymorphism ( $1 \mathrm{G}$ and $2 \mathrm{G}$ ) are formed by an insertion/deletion of guanine at position - 1607 . The presence of $2 \mathrm{G}$ creates the sequence 5'AAGGAT3', which is the consensus sequence of the E-twenty six family of transcription factors[12]. Thus, the $2 \mathrm{G}$ allele leads to increased transcriptional activity and MMP-1 expression.

Several studies investigated the relationships of MMP-1 (-1607 1G/2G)(rs1799750) polymorphism with increased knee OA risk in different countries and draw different conclusions[11, 13-16]. Therefore, we conducted a meta-analysis to assess the effect of the MMP-1 (-1607 $1 \mathrm{G} / 2 \mathrm{G}$ )(rs1799750) polymorphism on the risk of knee OA. The purpose of this study was to evaluate the association studies on MMP-1 (-1607 1G/2G)(rs1799750) polymorphism and knee OA and to estimate the common genetic effect of the polymorphism.

\section{Methods}

\subsection{Search strategy}

PubMed, Embase, Medline, Cochrane Library, Web of science, Google Scholar CNKI and Wanfang database were systematically searched to identify studies published from January 1990 to June 2019 and to retrieve the genetic association studies on knee OA. The terms 'Matrix metalloproteinase', 'MMP-1', 'SNP', 'polymorphism', 'knee', 'osteoarthritis', and 'OA' were used to find all publications reporting MMP-1 (-1607 1G/2G) (rs1799750) gene polymorphisms and knee OA risk. No language or other restrictions were placed on the search. Full text was obtained if the abstract was insufficient to allow us to include or exclude a study. Furthermore, the reference lists of all the related citations were examined to identify any initially omitted studies.

\subsection{Inclusion and exclusion criteria}


Two researchers screened the relevant investigations and further determined the eligible studies which met the following inclusion criteria: (1) case-control study on humans; (2) study evaluating the association between MMP-1 (-1607 1G/2G) (rs1799750) gene polymorphisms and susceptibility to knee OA; and (3) study with sufficient genetic frequency for extraction. The exclusion criteria were as follows: (1) insufficient data on genotype or allele frequency for calculation of odds ratio; (2) review or case report; and (3) duplicate or overlapping publication. All questionable publications were discussed and addressed by consensus. In cases of uncertainty regarding any of the above essential information, the full article was retrieved for further scrutiny, or the authors of the individual trials were contacted directly for further information when necessary.

\subsection{Data extraction}

Two researchers extracted all data independently according to the criteria described above. We developed a data extraction sheet including year of publication, the first author's name, OA region, ethnicity, source of control groups, genotype, and allele frequency. Any controversies of the data were discussed within our research team and the authors reached a consensus on all items.

\subsection{Study quality assessment}

The methodological quality of the studies was assessed using a modified version of the Jadad Scale (0 ["very poor"] to 7 ["rigorous"]). The modified version of Jadad Scale includes four domains: randomization, concealment of allocation, double blinding, withdrawals and dropouts (Figure 2). The assessment was independently performed by two authors.

\subsection{Statistical analysis}

Pooled odds ratios (ORs) with 95\% confidence intervals (Cls) were calculated to assess the association between MMP-1 (-1607 1G/2G) (rs1799750) gene polymorphisms and knee OA susceptibility. The observed genotype frequencies in control groups of the MMP-1 (-1607 1G/2G) (rs1799750) gene polymorphisms were assessed for Hardy Weinberg equilibrium (HWE) by using the Chi-square test. Three genetic models were used: (1) allele model; (2) recessive model; (3) dominant model. $P<0.05$ was considered significant. Heterogeneity assumption across studies was assessed by using the $Q$ statistic with its $P$-value and $I^{2}$ statistic. If $I^{2}<50 \%$ and $P>0.10$, a fixed effects model was used in the calculations; otherwise, a random effects model was applied[17-18]. Subgroup analysis were carried out on the basis of ethnicity. Potential publication bias was assessed with Begg's test[19].Sensitivity analysis by omitting each study in turn to determine the impact on the heterogeneity test and assessing the stability of the overall results. All statistical analyses were conducted in Stata15.1 (Stata Corporation, College Station, TX, U.S.A.).

\section{Results}

\subsection{Characteristics of the included studies}

The online search yielded 239 records, of which 64 duplicates were removed. Then 144 of the 175 remaining records were excluded after reviewing of titles and abstracts. The remaining 31 articles were sent for full text review, which excluded 11 articles without relevant to association between MMP-1 gene with OA, 8 not relevant to knee OA, 5 not about -1607 1G/2G polymorphism and 2 not case-control study (Figure 1). Finally, we identified five case-control studies about the association between MMP-1 (-1607 1G/2G) (rs1799750) gene polymorphisms and OA. Our meta-analysis involved a total of 924 knee OA cases and 928 controls. The distribution of genotypes of all the studies was in agreement with HWE. More characteristics of the included articles are shown in Table 1.

\subsection{Meta-analysis}

Based on the test results of heterogeneity, we use random effect model to make this meta-analysis. The result of the association betweenMMP-1 (-1607 1G/2G) (rs1799750) gene polymorphisms and the risk of knee OA and the heterogeneity test are shown in Table 2. The results suggested that the MMP-1 (-1607 1G/2G) (rs1799750) gene polymorphisms were not associated with knee OA risk in all genetic models (Allele model OR $=1.22,95 \% \mathrm{Cl}$ : 0.72-1.76, $\mathrm{p}=0.615$, Recessive model $\mathrm{OR}=1.12,95 \% \mathrm{Cl}: 0.70-2.15, \mathrm{p}=0.486$, and Dominant model $\mathrm{OR}=1.14,95 \% \mathrm{Cl}: 0.64-2.04, \mathrm{p}=0.659$, Figure $3-5)$.

We then performed sub-group analyses to investigate the effect of the ethnicity with the risk of the knee OA. The results showed that there was no significant difference between MMP-1 (-1607 1G/2G) (rs1799750) gene polymorphisms and the risk of knee OA in both Asian and Caucasian populations (Table 2).

Sensitivity analysis was used to determine the pooled ORs regarding the effects of this SNP on knee OA risk by omitting each study in turn to determine the effect on the heterogeneity test and evaluate the stability of the overall results, the results indicated that our data were

Page 3/11 
stable and credible.

It was difficult to interpret the funnel plot, which is used to detect publication bias, because the number of studies included in the analysis was relatively small. Begg's test were performed to quantitatively evaluate the publication bias of literatures on knee OA. The results of the Begg's test suggested that there was no evidence of publication bias in the meta-analyses of association between the MMP-1 (-1607 $1 G / 2 G)(r s 1799750)$ gene polymorphisms and risk of $O A(p>0.05$ Table 2$)$.

\section{Discussion}

The most important finding was that there is no association between the polymorphism of MMP-1rs 1799750 polymorphism with the risk of knee osteoarthritis. This contradicts our traditional view that MMP-1 is involved in the occurrence of knee osteoarthritis and is a risk factor for the knee OA.

The definite mechanisms of the knee OA remain unknown, but many studies have shown that genetic factors are considered to be strong determinants with them and the occurrence of knee osteoarthritis is related to inflammatory and cytokines[20-22]. A kind of conventional viewpoints is that inflammatory mechanism plays a crucial role in the pathogenesis and evolution of cartilage degeneration and expression of inflammatory reaction[23-25]. MMP-1 is produced by synovial cells, chondrocytes, and osteoblasts, which can degrade extracellular matrix collagen and mediate cartilage destruction[7-8]. Expression of MMP-1 is low in normal cells that leads to healthy cartilage remodeling. In pathological conditions, the level of MMP-1 expression increases considerably, resulting in aberrant connective tissue destruction[10]. MMP-1 is expressed at higher levels in OA chondrocytes than in normal chondrocytes, suggesting a predominant role of MMP-1 in OA pathogenesis[26].In this way, MMP-1 gene is considered to be associated with OA.

Recent studies have shown that some functional polymorphisms of MMPs, including MMP-1 (-1607 1G/2G) (rs1799750) polymorphism, have been associated with the risk of knee OA[11-16].However, due to the limited sample size of these studies, previous single studies may not be effective, so conflicting research results have been obtained, especially considering the heterogeneity of the study and different races, clinical heterogeneity and genetic diversity of other causes. Therefore, we conducted this meta-analysis to provide more confident evidence. Our data showed that MMP1 gene polymorphism do not increase the risk of OA. Furthermore, stratification analyses by ethnicity also indicated that this polymorphism do not increases the risk of knee OA in different ethnics.

In our study, 5 eligible studies, including 924 cases and 928 controls, were identified and analyzed. We demonstrated the association between MMP-1 (-1607 1G/2G) (rs1799750) and the knee OA risk by a meta-analysis to obtain a powerful conclusion. Our research suggests that MMP-1 (-1607 1G/2G) (rs1799750) polymorphism is not a risk or protective factor for knee osteoarthritis $(p>0.05)$. It is believed that $2 \mathrm{G}$ genotype can promote the high expression of MMP-1, which may be a risk factor for the occurrence of osteoarthritis. In our study, the $2 \mathrm{G}$ allele in case groups was indeed higher than that in the control groups, but the difference was not statistically significant $(57 \%$ vs. $51 \%, p=0.615)$. The possible reason for this conclusion may be that the occurrence of knee osteoarthritis is the ultimate result of a variety of factors and genes, and a single gene may have little influence on this result. Secondly, there may be unknown alleles affecting the expression of $1 \mathrm{G} / 2 \mathrm{G}$ gene, and $-16071 \mathrm{G} / 2 \mathrm{G}$ is not the only factor affecting the expression of MMP-1 in the population. Third, although MMP-1 can mediate cartilage degeneration, it is not a direct determinant of osteoarthritis. Many cytokines of MMP family are involved in cartilage metabolism. The destruction of articular cartilage is the common result of many cytokines. MMP-1 cannot directly reflect the effect of cartilage metabolic changes on osteoarthritis. Subgroup analysis also confirmed that MMP-1 did not increase the risk of osteoarthritis among different ethnic groups.

Before our study, there was a meta-analysis providing comprehensive insights into the effects of the MMP-1 (-1607 1G/2G) (rs1799750)and risk of OA in European and African, with very highly significant association for the OA as measured by homozygote, heterozygote, dominant model comparison[27].The reasons why our research has come to different conclusions may be the following. First of all, our research has more stringent criteria for retrieval and exclusion, including a recently published literature. Secondly, the study we included was limited to knee osteoarthritis, not other types of osteoarthritis, making the results more representative. Thirdly, we used race subgroup analysis to analyze the effects of different races on gene expression in knee OA and we found that there was no significant difference between MMP-1 and the risk of knee osteoarthritis in different ethnics.

There are still some limitations in our paper. Firstly, our several genetic models have great heterogeneity when combining OR values, which may affect the accuracy of the article. For this reason, we used random effect model to combine OR values and conduct sensitivity analysis to reduce the impact of heterogeneity. Secondly, although five papers have been included in the study, the data scale is still small, and further experiments are needed to verify this conclusion. Thirdly, the study is limited to the study of MMP-1 (-1607 1G/2G) (rs1799750), and If we included more factors, the result might be more comprehensive.

Page $4 / 11$ 


\section{Conclusion}

Our results do not support a genetic association between MMP-1 (-1607 1G/2G) (rs1799750) polymorphisms and the risk of knee OA. Although itis possible that these individual SNPs could be associated with knee OA, a large number of studies may be necessary to verify this association between the susceptibility of knee OA in different populations and environmental factors.

\section{Abbreviations}

MMP: Matrix metalloproteinase OR: odds ratio OA: osteoarthritis

SNPs: single nucleotide polymorphisms HWE: Hardy Weinberg equilibrium

\section{Declarations}

\section{Ethics approval and consent to participate}

All procedures performed in studies involving human participants were in accordance with the ethical standards of the institutional and/or national research committee and with the 1964 Helsinki declaration and its later amendments or comparable ethical standards.

\section{Consent for publication}

Not applicable.

\section{Availability of data and materials}

Not applicable.

\section{Competing interests}

The authors declare that they have no competing interests.

\section{Funding}

This study was funded by National Natural Science Foundation of China (grant number 81972130冈81703896囚81972107)

The Fund's role is to provide review and publishing costs.

\section{Author contributions}

FF-L and QD-Z contributed to the conception and design. WS-G and QD-Z did interpretation. XW-S and FFL did the data collection and analysis. FF-L and XW-S wrote the article. QD-Z and WG-W did the final approval of the version to be submitted.

\section{Acknowledgements}

Not applicable.

\section{References}

1. G. Peat, R. McCarney, P. Croft, Knee pain and osteoarthritis in older adults: a review of community burden and current use of primary health care, ANN RHEUM DIS, 60 (2001) 91-7.

2. L. Michou, Genetics of digital osteoarthritis, JOINT BONE SPINE, 78 (2011) 347-51.

3. Z.C. Tong, Y. Liu, B. Chen, L. Yan, D.J. Hao, Association between MMP3 and TIMP3 polymorphisms and risk of osteoarthritis, ONCOTARGET, 8 (2017) 83563-83569.

4. S. Honsawek, S. Malila, P. Yuktanandana, A. Tanavalee, B. Deepaisarnsakul, J. Parvizi, Association of MMP-3 (-1612 5A/6A) polymorphism with knee osteoarthritis in Thai population, RHEUMATOL INT, 33 (2013) 435-439.

5. W. Guo, P. Xu, T. Jin, J. Wang, D. Fan, Z. Hao, Y. Ji, S. Jing, C. Han, Du J, D. Jiang, S. Wen, J. Wang, MMP-3 gene polymorphisms are associated with increased risk of osteoarthritis in Chinese men, Oncotarget, 8 (2017) 79491-79497. 
6. G. Murphy, H. Nagase, Reappraising metalloproteinases in rheumatoid arthritis and osteoarthritis: destruction or repair? Nat Clin Pract Rheumatol, 4 (2008) 128-35.

7. A. Kaspiris, L. Khaldi, T.B. Grivas, E. Vasiliadis, I. Kouvaras, S. Dagkas, E. Chronopoulos, E. Papadimitriou, Subchondral cyst development and MMP-1 expression during progression of osteoarthritis: an immunohistochemical study, Orthop Traumatol Surg Res, 99 (2013) 523-9.

8. P.S. Burrage, K.S. Mix, C.E. Brinckerhoff, Matrix metalloproteinases: role in arthritis, Front Biosci, 11 (2006) $529-43$.

9. J.L. Rutter, T.I. Mitchell, G. Buttice, J. Meyers, J.F. Gusella, L.J. Ozelius, C.E. Brinckerhoff, A single nucleotide polymorphism in the matrix metalloproteinase-1 promoter creates an Ets binding site and augments transcription, CANCER RES, 58 (1998) 5321-5.

10. M.P. Vincenti, C.E. Brinckerhoff, Transcriptional regulation of collagenase (MMP-1, MMP-13) genes in arthritis: integration of complex signaling pathways for the recruitment of gene-specific transcription factors, Arthritis Res, 4 (2002) 157-64.

11. R. Geng, Y. Xu, W. Hu, H. Zhao, The association between MMP-1 gene rs1799750 polymorphism and knee osteoarthritis risk, BIOSCIENCE REP, 38 (2018) BSR20181257.

12. J.L. Rutter, T.I. Mitchell, G. Buttice, J. Meyers, J.F. Gusella, L.J. Ozelius, C.E. Brinckerhoff, A single nucleotide polymorphism in the matrix metalloproteinase-1 promoter creates an Ets binding site and augments transcription, CANCER RES, 58 (1998) $5321-5$.

13. I.Ö. Barlas, M. Sezgin, M.E. Erdal, G. Sahin, H.C. Ankarali, Z.M. Altintas, E. Türkmen, Association of $(-1,607) 1 \mathrm{G} / 2 \mathrm{G}$ polymorphism of matrix metalloproteinase-1 gene with knee osteoarthritis in the Turkish population (knee osteoarthritis and MMPs gene polymorphisms), RHEUMATOL INT, 29 (2009) 383-388.

14. H.Y. Yang, S.Y. Chuang, W.H. Fang, G.S. Huang, C.C. Wang, Y.Y. Huang, M.Y. Chu, C. Lin, W. Su, C.Y. Chen, Y.T. Yang, S.L. Su, Effect of RAGE polymorphisms on susceptibility to and severity of osteoarthritis in a Han Chinese population: a case-control study, Genetics and Molecular Research, 14 (2015) 11362-11370.

15. P. Lepetsos, A. Pampanos, E. Kanavakis, M. Tzetis, D. Korres, A.G. Papavassiliou, N. Efstathopoulos, Association ofMMP-1-1607 1G/2G (rs1799750) polymorphism with primary knee osteoarthritis in the Greek population, J ORTHOP RES, 32 (2014) $1155-1160$.

16. S.H. Abd-Allah, S.M. Shalaby, H.F. Pasha, A.S. El-Shal, A.M. Abou El-Saoud, Variation of Matrix Metalloproteinase 1 and 3 Haplotypes and Their Serum Levels in Patients with Rheumatoid Arthritis and Osteoarthritis, GENET TEST MOL BIOMA, 16 (2012) 15-20.

17. N. MANTEL, W. HAENSZEL, Statistical aspects of the analysis of data from retrospective studies of disease, J Natl Cancer Inst, 22 (1959) 719-48.

18. R. DerSimonian, N. Laird, Meta-analysis in clinical trials revisited, CONTEMP CLIN TRIALS, 45 (2015) 139-45.

19. M. Egger, S.G. Davey, M. Schneider, C. Minder, Bias in meta-analysis detected by a simple, graphical test, BMJ, 315 (1997) $629-34$.

20. F. Capsoni, A.M. Ongari, C. Lonati, R. Accetta, S. Gatti, A. Catania, alpha-Melanocyte-stimulating-hormone (alpha-MSH) modulates human chondrocyte activation induced by proinflammatory cytokines, BMC Musculoskelet Disord, 16 (2015) 154.

21. M.H. Moon, J.K. Jeong, Y.J. Lee, J.W. Seol, C.J. Jackson, S.Y. Park, SIRT1, a class III histone deacetylase, regulates TNF-alpha-induced inflammation in human chondrocytes, Osteoarthritis Cartilage, 21 (2013) 470-80.

22. T.L. Huang, C.H. Yang, G. Yanai, J.Y. Liao, S. Sumi, K.C. Yang, Synergistic effect of I-ascorbic acid and hyaluronic acid on the expressions of matrix metalloproteinase-3 and -9 in human chondrocytes, J Biomed Mater Res B Appl Biomater, 106 (2018) 1809 1817.

23. H.Q. Hao, J.F. Zhang, Q.Q. He, Z. Wang, Catirlage oligomeric matrix protein, C-terminal cross-linking telopeptide of type II collagen, and matrix metalloproteinase-3 as biomarkers for knee and hip osteoarthritis (OA) diagnosis: a systematic review and meta-analysis, Osteoarthritis Cartilage, (2018).

24. Y. Wan, W. Li, Z. Liao, M. Yan, X. Chen, Z. Tang, Selective MMP-13 inhibitors: promising agents for the therapy of Osteoarthritis, CURR MED CHEM, (2018).

25. R. Nakagawa, R. Akagi, S. Yamaguchi, T. Enomoto, Y. Sato, S. Kimura, Y. Ogawa, A. Sadamasu, S. Ohtori, T. Sasho, Single vs. repeated matrix metalloproteinase-13 knockdown with intra-articular short interfering RNA administration in a murine osteoarthritis model, CONNECT TISSUE RES, (2018) 1-9.

26. L.C. Tetlow, D.J. Adlam, D.E. Woolley, Matrix metalloproteinase and proinflammatory cytokine production by chondrocytes of human osteoarthritic cartilage: associations with degenerative changes, Arthritis Rheum, 44 (2001) 585-94.

27. P. Xu, J. Wang, Z. Hao, Review Acticle The polymorphism of rs1799750 in matrix metallopeptidase 1 (MMP-1) gene contributes to osteoarthritis risk: a meta-analysis, INT J CLIN EXP MED, 10 (2016) 18824-18833.

\section{Tables}

Page 6/11 
Table 1. Characteristics of the included studies

\begin{tabular}{|c|c|c|c|c|c|c|c|c|c|c|c|}
\hline \multirow[t]{2}{*}{ Authors } & \multirow[t]{2}{*}{ Years } & \multicolumn{3}{|l|}{ Case } & \multicolumn{3}{|l|}{ Control } & \multirow[t]{2}{*}{ Genotype } & \multirow[t]{2}{*}{ Ethnics } & \multirow[t]{2}{*}{ Region } & \multirow{2}{*}{$\begin{array}{l}\text { HWE } \\
\text { test } \\
\\
\mathrm{P} \\
\text { value }\end{array}$} \\
\hline & & $2 G / 2 G$ & $1 \mathrm{G} / 1 \mathrm{G}$ & $1 G / 2 G$ & $2 G / 2 G$ & $1 \mathrm{G} / 1 \mathrm{G}$ & $1 G / 2 G$ & & & & \\
\hline Geng[11] & 2018 & 76 & 76 & 154 & 61 & 139 & 201 & $\begin{array}{l}\text { MMP-1 } \\
\text { gene-- } \\
1607\end{array}$ & Asian & $\begin{array}{l}\text { knee } \\
\text { OA }\end{array}$ & 0.401 \\
\hline Yang[14] & 2015 & 92 & 27 & 88 & 98 & 20 & 89 & $\begin{array}{l}\text { MMP-1 } \\
\text { gene- } \\
1607\end{array}$ & Asian & $\begin{array}{l}\text { knee } \\
\text { OA }\end{array}$ & 0.974 \\
\hline Lepetsos[15] & 2014 & 63 & 28 & 64 & 47 & 34 & 58 & $\begin{array}{l}\text { MMP-1 } \\
\text { gene-- } \\
1607\end{array}$ & Caucasian & $\begin{array}{l}\text { knee } \\
\text { OA }\end{array}$ & 0.062 \\
\hline Somia[16] & 2012 & 27 & 27 & 46 & 10 & 50 & 40 & $\begin{array}{l}\text { MMP-1 } \\
\text { gene- } \\
1607\end{array}$ & Caucasian & $\begin{array}{l}\text { knee } \\
\text { OA }\end{array}$ & 0.634 \\
\hline Barlas[13] & 2008 & 68 & 31 & 57 & 52 & 5 & 24 & $\begin{array}{l}\text { MMP-1 } \\
\text { gene-- } \\
1607\end{array}$ & Caucasian & $\begin{array}{l}\text { knee } \\
\text { OA }\end{array}$ & 0.337 \\
\hline
\end{tabular}

Table 2. OR and $95 \% \mathrm{Cl}$ for knee OA and MMP-1 under different genetic models

\begin{tabular}{|c|c|c|c|c|c|c|c|}
\hline \multirow[t]{2}{*}{ Genetic model } & \multirow[t]{2}{*}{ Subgroups } & \multirow[t]{2}{*}{ Studies } & \multicolumn{3}{|c|}{ Association test } & \multirow{2}{*}{$\begin{array}{l}\text { Heterogeneity } \\
\text { P value }\end{array}$} & \multirow{2}{*}{$\begin{array}{l}\text { Begg's test } \\
\text { P value }\end{array}$} \\
\hline & & & OR & $95 \% \mathrm{Cl}$ & $P$ value & & \\
\hline \multirow{3}{*}{$\begin{array}{l}\text { Allele model } \\
\text { (2G vs. } 1 G)\end{array}$} & Total & 5 & 1.12 & $0.72-1.76$ & 0.615 & 0.000 & 0.624 \\
\hline & Asian & 2 & 1.14 & $0.68-1.94$ & 0.614 & 0.008 & 0.317 \\
\hline & Caucasian & 3 & 1.1 & $0.45-2.68$ & 0.83 & 0.000 & 0.062 \\
\hline \multirow{3}{*}{$\begin{array}{l}\text { Recessive model } \\
(2 \mathrm{G} 2 \mathrm{G} \text { vs } 1 \mathrm{G} 2 \mathrm{G}+1 \mathrm{G} 1 \mathrm{G})\end{array}$} & Total & 5 & 1.22 & $0.70-2.15$ & 0.486 & 0.000 & 0.624 \\
\hline & Asian & 2 & 1.28 & $0.63-2.62$ & 0.495 & 0.003 & 0.317 \\
\hline & Caucasian & 3 & 1.21 & $0.42-3.48$ & 0.726 & 0.000 & 0.062 \\
\hline \multirow{3}{*}{$\begin{array}{l}\text { Dominant model } \\
(2 \mathrm{G} 2 \mathrm{G}+1 \mathrm{G} 2 \mathrm{G} \text { vs } 1 \mathrm{G} 1 \mathrm{G})\end{array}$} & Total & 5 & 1.14 & $0.64-2.04$ & 0.659 & 0.000 & 0.142 \\
\hline & Asian & 2 & 1.12 & $0.51-2.46$ & 0.784 & 0.022 & 0.317 \\
\hline & Caucasian & 3 & 1.09 & $0.36-3.34$ & 0.876 & 0.000 & 0.062 \\
\hline
\end{tabular}

\section{Figures}




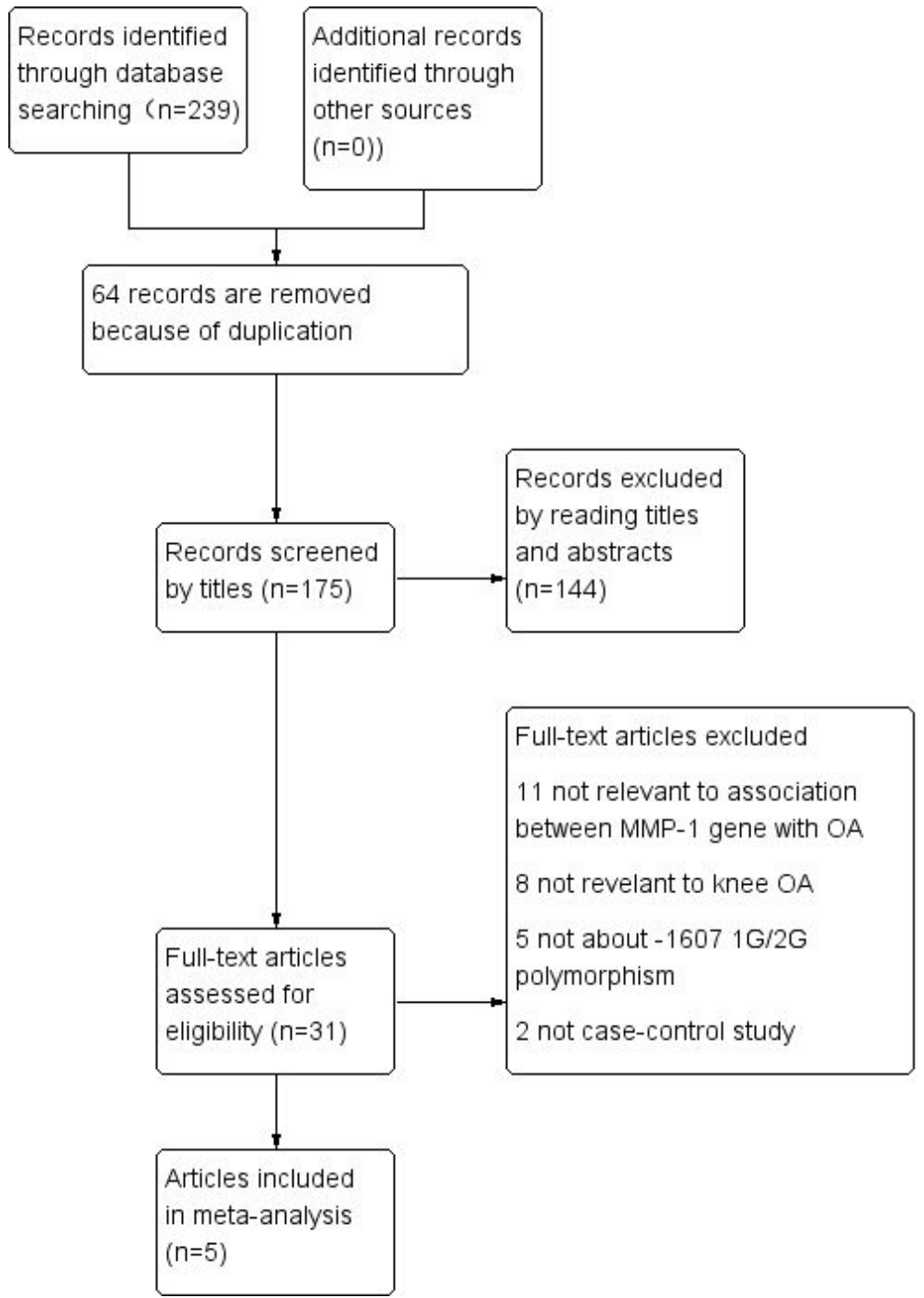

\section{Figure 1}

Flowchart of the literature search and selection for the present study

\begin{tabular}{|c|c|c|c|c|c|}
\hline 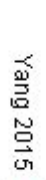 & 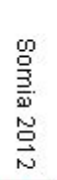 & 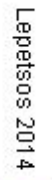 & 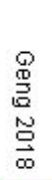 & 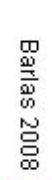 & \\
\hline (1) & (1) & $\odot$ & $\odot$ & $\odot$ & Random sequence generation (selection bias) \\
\hline$\sim$ & $\sim$ & $\sim$ & $\odot$ & + & Allocation concealment (selection bias) \\
\hline$\sim$ & $\sim$ & $\sim$ & $\sim$ & $\sim$ & Blinding of participants and personnel (performance bias) \\
\hline$\sim$ & $\sim$ & $\sim$ & $\sim$ & $\sim$ & Blinding of outcome assessment (detection bias) \\
\hline$\odot$ & + & $\odot$ & $\odot$ & $\odot$ & Incomplete outcome data (attrition bias) \\
\hline+ & + & $\odot$ & $\odot$ & + & Selective reporting (reporting bias) \\
\hline+ & + & $\odot$ & $\odot$ & $\odot$ & Other bias \\
\hline
\end{tabular}

\section{Figure 2}

Results of the methodological quality evaluations. Green indicates that the criterion is satisfied. Yellow indicates that it is unclear whether the criterion is satisfied or not. Red indicates that the study did not meet the criterion. 
ID

OR $(95 \% \mathrm{Cl}) \quad$ Weight

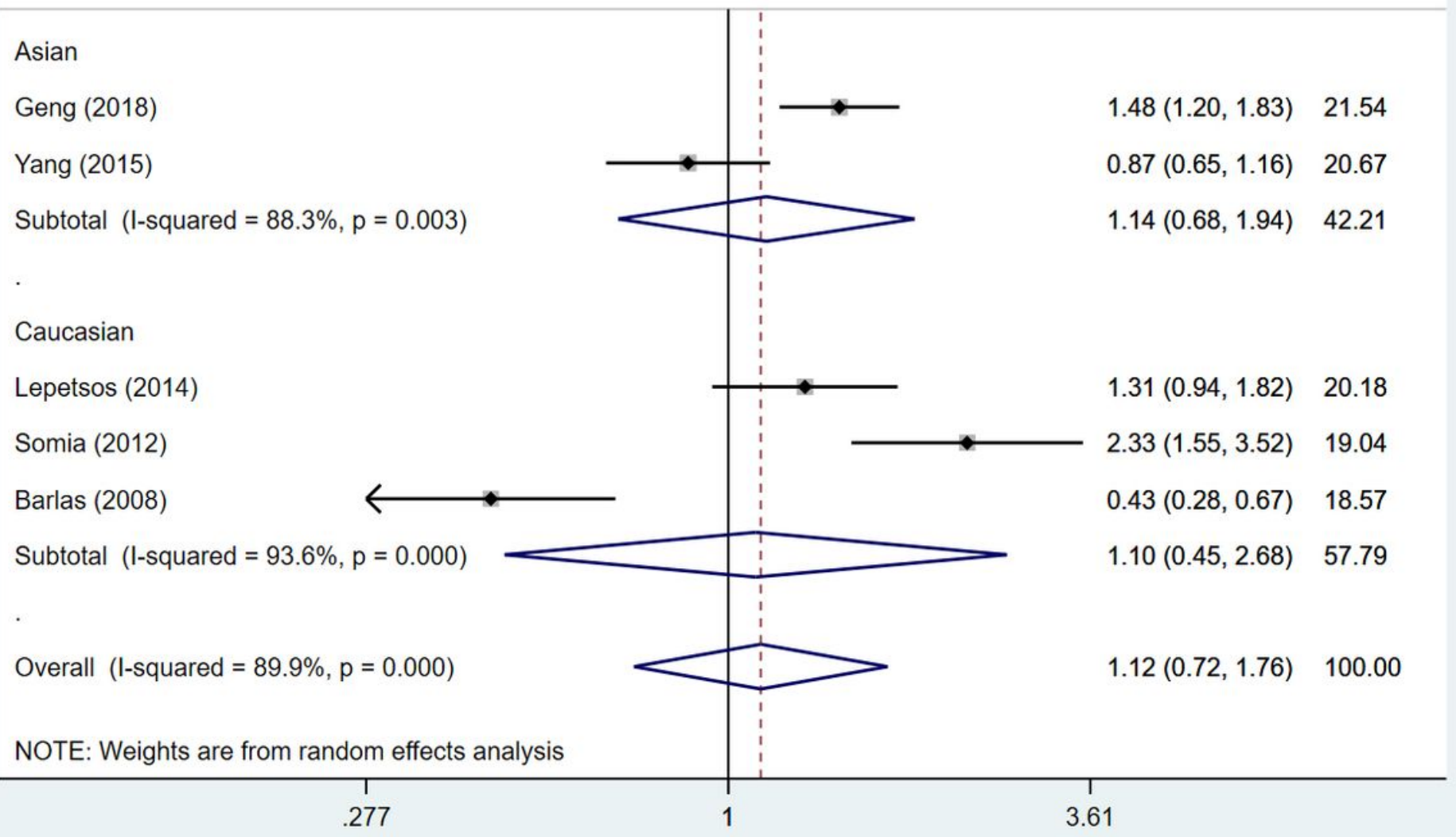

\section{Figure 3}

Forest plot showing OR for the associations between the MMP-1 polymorphism and knee OA risk (Allele model) 
ID

OR $(95 \% \mathrm{Cl}) \quad$ Weight

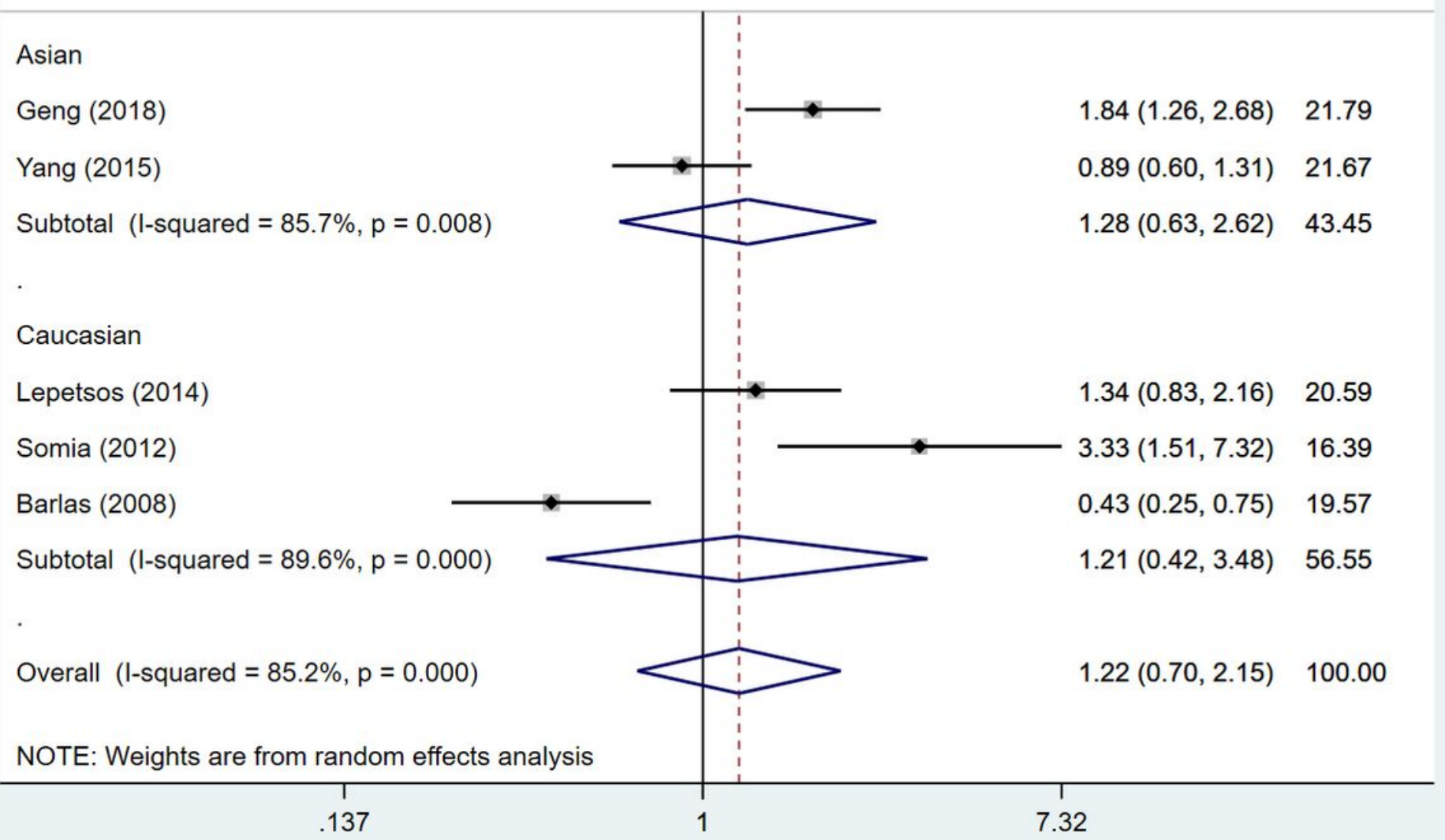

\section{Figure 4}

Forest plot showing OR for the associations between the MMP-1 polymorphism and knee OA risk (Recessive model) 


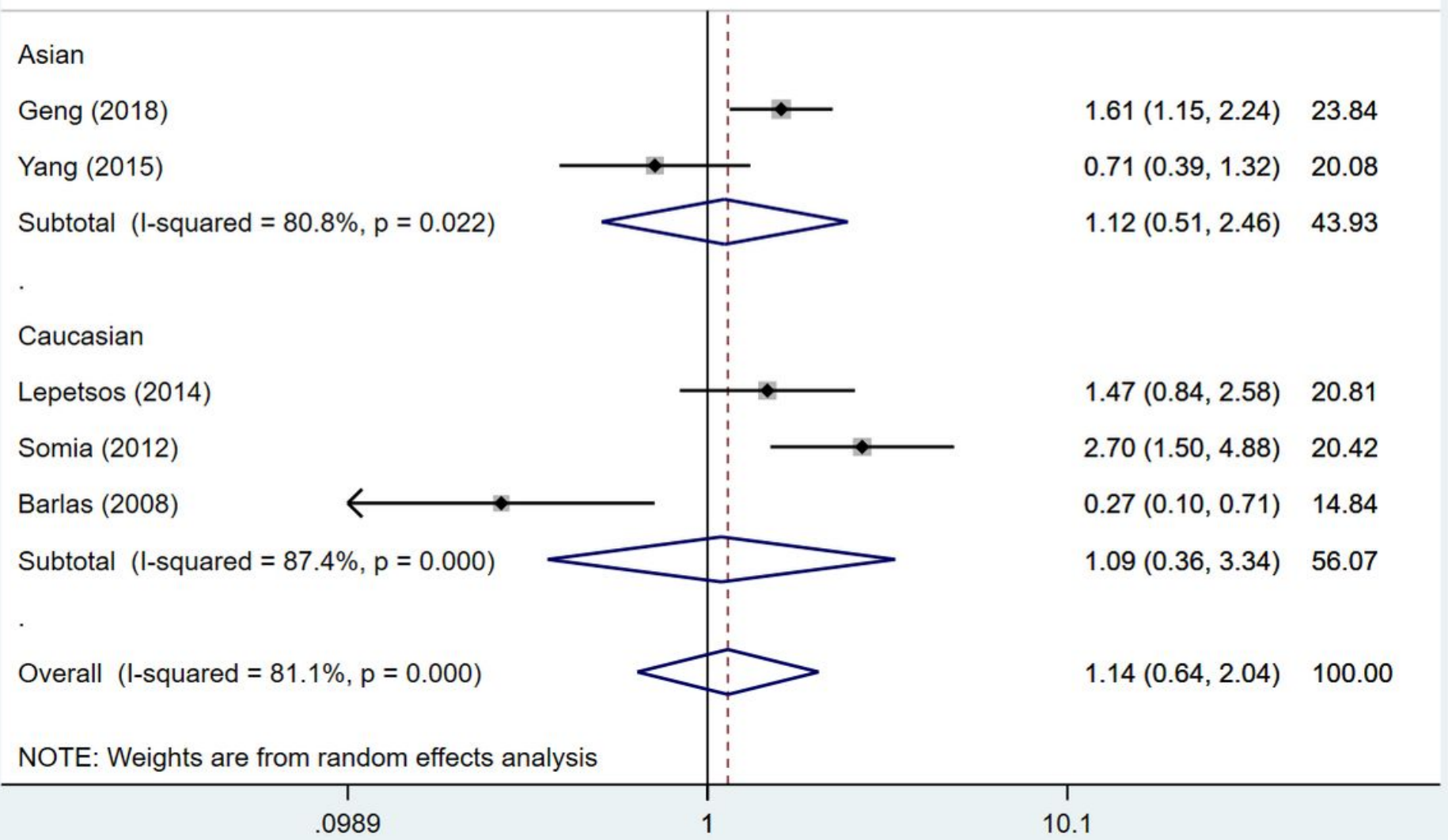

\section{Figure 5}

Forest plot showing OR for the associations between the MMP-1 polymorphism and knee OA risk (Dominant model)

\section{Supplementary Files}

This is a list of supplementary files associated with this preprint. Click to download.

- PRISMA2009checklist.doc

- PRISMA2009checklist.doc 